Ger J Exerc Sport Res 2022 $52: 447-460$ https://doi.org/10.1007/s12662-021-00782-y Received: 23 April 2021

Accepted: 23 October 2021

Published online: 1 December 2021

(c) The Author(s) 2021

\author{
Moritz Mödinger ${ }^{1}(\mathbb{D}) \cdot$ Alexander Woll $^{1} \cdot$ Ingo Wagner $^{2}$ (D) \\ ${ }^{1}$ Institut für Sport und Sportwissenschaft (IfSS) \& Forschungszentrum für den Sport von Kindern und \\ Jugendlichen (FoSS), Karlsruher Institut für Technologie (KIT), Karlsruhe, Germany \\ ${ }^{2}$ Zentrum für Lehrer*innenbildung (ZLB) \& Institut für Sport und Sportwissenschaft (IfSS), Karlsruher \\ Institut für Technologie (KIT), Karlsruhe, Germany
}

\title{
Video-based visual feedback to enhance motor learning in physical education-a systematic review
}

\section{Theoretical background and state of research}

Motor learning is fundamental to the individual development process and is possible at all ages (Voelcker-Rehage, 2008); nevertheless, the prepubertal phase, and therefore the school period, is considered particularly suitable for introducing motor learning processes (Hirtz \& Starosta, 2002). Due to this fundamental importance, the question of how movements are learned has been the subject of numerous scientific investigations and has led to various theories.

However, few studies have investigated the effectiveness of visual feedback using videos in physical education in school settings, which comprise more heterogeneous target groups in terms of performance and motivation than voluntary settings like extracurricular sports activities. Nevertheless, as effective movement learning supported by visual feedback is meaningful for physical education, related systematic guidance for teachers to provide such feedback is needed. For these reasons it is important to investigate whether visual feedback using videos is suitable for daily use in physical education classes and which methodological approach is the most effective regarding motor learning.
In their general orientation motor approaches are to be distinguished from action approaches (for an overview see Birklbauer, 2006). The approach that shaped the scientific discussion in the second half of the 20th century was the motor approach (Wewetzer, 2008). The motor approach is usually based on an information-theoretical approach. Motion representations are stored centrally and can be retrieved on demand (Schmidt, 1975). The learning process focuses on the reinforcement and parameterization of movement representations. A technical model gives orientation, and visual or verbal feedback helps to reduce errors (Wewetzer, 2008).

For the initiation of motor learning processes, feedback as information "relating to successful and incorrect aspects of movements already performed" (Olivier \& Rockmann, 2003, p. 184) is an essential influencing factor in addition to observation exercises, self-directed practice, and conscious control of attention (Wulf, Shea, \& Lewthwaite, 2010). Since the information is not obtained from the learner themselves, but is fed back from external sources, it is extrinsic in nature. Extrinsic information is conveyed via different motor learning tasks, which differ in terms of their objectives (modeling, movement topology or parameter learning) and the amount of informa- tion needed regarding what is to be learned (modeling $>$ movement topology $>$ parameter learning). Modeling focuses on spatial kinematic movement characteristics and the relative duration of partial movements. In teaching a movement topology, information regarding the movement goal (criterion value information) and how this can be achieved on the basis of the current execution (correcting information) is primarily used. Parameter learning, on the other hand, focuses on information that provides information about the current execution (actual value information) and the deviation from an ideal performance (discrepancy information) (Blischke, Marschall, Müller, \& Daugs, 1999). Newell (1991) also discusses transitional information, which is information about the "what" and "how" of the movement, when the learner is aware of the current and target state, but is not able to improve his or her own performance (Blischke et al., 1999).

However, feedback unfolds its effect only in interaction with other parameters. The way the information is processed, the timing of the feedback process, and the frequency of feedback are important and partially influence each other. The amount of information to be conveyed subsequently affects the timing of feedback. In modeling, the time between trial and feedback information should not exceed $45 \mathrm{~s}$ (parameter learning $\leq 15 \mathrm{~s}$ ), and the new trial should be carried out within 
Table 1 Categories and keywords for the literature search

\begin{tabular}{ll}
\hline Category & Keywords \\
\hline $\begin{array}{l}\text { Task—what? } \\
\text { Modality-how? }\end{array}$ & $\begin{array}{l}\text { Feedback, modeling, motor learning } \\
\text { Video*, tablet*, videotape*, mobile device*, video analysis, handheld } \\
\text { device*, observation }\end{array}$ \\
\hline Setting—where? & $\begin{array}{l}\text { Physical education, school sport*, gymnastic education, gymnastic in- } \\
\text { struction, elementary school, primary school, secondary school, middle } \\
\text { school, high school }\end{array}$ \\
\hline Population—who? & $\begin{array}{l}\text { Sport* teacher, gym teacher, PE teacher, physical education teacher, } \\
\text { student*, pupil*, children* }\end{array}$ \\
\hline Asterisks also include the plural
\end{tabular}

the subsequent $120 \mathrm{~s}$ (parameter learning $\leq 20 \mathrm{~s}$ ). In this context, a relative feedback frequency of $25 \%$ distributed over the learning process seems to be sufficient to implement learning processes without loss compared to a higher feedback frequency (Blischke et al., 1999; Marschall, Bund, \&Wiemeyer, 2007) and to prevent guidance at the same time (Schmidt, 1991). In modeling, additional corrective information (Kernodle \& Carlton, 1992), repeated observation (3-5 times), or preferably, a slow motion sequence ( $\leq 25 \%$ of normal speed), as well as pictures (semi-abstract line drawings) support the learning process (Blischke et al., 1999). To teach a basic movement structure, short, precise verbal cues (about 20 words) and easy-tounderstand combinations of text and picture (picture above text, read from left to right) are helpful. Zetou, Kourtesis, Getsiou, Michalapoulou, and Kioumourtzoglou (2009) also point out that verbal cues must be linguistically appropriate for the age group. If only a partial movement is to be improved, it is recommended to limit the feedback process to one parameter (Blischke et al., 1999).

Although auditory, haptic, and visual feedback offer a variety of ways to provide feedback (Sigrist, Rauter, Riener, \& Wolf, 2013) digitization has recently increased the focus on visual feedback methods that use digital devices with applications for video analysis, such as Coach's Eye, the Hudl Technique, or Dartfish, to support the learning process (Kok, Komen, van Capelleveen, \& van der Kamp, 2020; Korban \& Künzell, 2019; Ste-Marie, Vertes, Rymal, \& Martini, 2011). The combination of visual feedback methods and digital devices made complex visualization techniques practical and versatile, as well as accessible to new audiences such as physical education teachers or amateur coaches.

In their characteristics of following a technique model and trying to minimize errors through repeated externally organized practice with respect to an ideal movement, visual feedback methods following Bandura and Walters (1977) show pronounced intersections with principles of motor approaches and thus cognitive learning theories.

Visual feedback in motor learning in general has been thoroughly investigated. As a form of augmented feedback (Swinnen, 1996) visual feedback overcomes problems associated with visual perception, sensory information (auditory, tactile, or proprioceptive), and the temporal availability of task-intrinsic feedback.

Several studies indicate that visual feedback may be effective and enhance motor learning in sport settings (Clark \& Ste-Marie, 2007; Rhoads, Da Matta, Larson, \& Pulos, 2014), although not all research findings support this view (Emmen, Wesseling, Bootsma, Whiting, \& van Wieringen, 1985; Rothstein \& Arnold, 1976).

Particularly as a component of multimodal feedback, visual feedback seems to offer fruitful opportunities (Sigrist et al., 2013). With regard to the cognitive processing of information, one might use the multimodal memory model of Engelkamp (1998). According to this model, the same perceptions recorded via different sensors result in a more intensive processing and storage of information (Engelkamp, 1998; Hoffmann \& Engelkamp, 2013). This does not contradict the findings of some studies that attribute an even greater potential to visual feedback than to verbal feedback
(Rhoads et al., 2014). Due to their better distinctiveness, pictures are supposedly better remembered than words (Hoffmann \& Engelkamp, 2013). However, opinions differ regarding the advantages of visual over verbal feedback (Kernodle, Johnson, \& Arnold, 2001).

There is an ongoing discussion about the most effective method of providing visual feedback. However, the effectiveness of a feedback method as initiating, improving, and maintaining learning progress depends on many influencing factors (Rhoads et al., 2014; Sigrist et al., 2013). For instance, different visual feedback methods differ among other things in the way the information is provided (pictures or video), in the origin of the information (own or others' presentation), as well as in the evaluation of the information (by experts or self-organized). Visual feedback can be achieved through self-modeling, by the practitioner analyzing their own movement executions, as well as through expert modeling, in which a video of an ideal movement execution is used to provide information. Sometimes a combination of both is used to superimpose the model on the movement execution (Korban \& Künzell, 2019). Despite evidence that different visualization methods can be effective for self-modeling (Kelley \& Miltenberger, 2016), expert modeling (Arbabi \& Sarabandi, 2016), and using both methods simultaneously (Baudry, Leroy, \& Chollet, 2006), reliable statements about a preferred method are difficult to make as they have rarely been compared directly.

The state of the research shows that there is evidence of the effective use of visual feedback in a number of research settings. In addition to sport settings (Guadagnoli, Holcomb, \& Davis, 2002; Kelley \& Miltenberger, 2016; Ste-Marie et al., 2011), positive examples can be found in school settings (Hitchcock, Dowrick, \& Prater, 2003; Prater, Carter, Hitchcock, \& Dowrick, 2012) or in mixed settings (Dowrick, 1999), including some with people with disabilities (Bellini \& Akullian, 2007). The entirety of these findings suggests a positive potential for physical education in schools, but very few studies have addressed the specific needs and conditions of physical 
education; yet, a consideration of these specific needs and conditions is essential for physical education teachers in relation to making motor learning effective and suitable for everyday use.

This is also illustrated by data from the Organisation for Economic Co-operation and Development (OECD; 2020) which shows an average class size of 21 for elementary schools and 23 for secondary schools. As physical education is a compulsory subject in schools in many countries, including Germany (Ministerium für Kultus, 2016), all students, regardless of their interests or inclinations, participate in the lessons, which, in addition to limited time resources, has an impact on learners' heterogeneity as well as their motivation. For example, many sports studies have relied on voluntary participation (Baudry et al., 2006), which is usually motivated by particular intentions that cannot be taken for granted in schools, despite motivation being an important factor in enhancing motor learning (Wulf \& Lewthwaite, 2016). Schools usually do not have access to elaborate, time-consuming video editing technology (Ste-Marie et al., 2011). Furthermore, small groups (Boyer, Miltenberger, Batsche, \& Fogel, 2009), consistently high performance levels (Baudry et al., 2006) and high intrinsic motivation only reflect the reality in schools to a limited extent.

As a systematic investigation of visually assisted video-based feedback in physical education has been lacking in research so far, this systematic review aims to summarize the research and answer questions regarding the general suitability of visual feedback, the best choice of methods (expert modeling and/or selfmodeling), and the comparability of circumstances for daily use in physical education.

The following research questions were deemed particularly important for assessing the effectiveness of different visual video-based feedback methods, as well as the comparability of different settings:

1. Is video-based visual feedback effec-

tive to enhance motor learning in physical education?

2. Is video-based visual feedback (expert modeling, self-modeling, or a combination of both) more effec- tive to enhance motor learning in physical education than solely verbal feedback?

3. Are the conditions of the analyzed studies comparable to those in regular school lessons?

\section{Methods}

A systematic search was carried out between November 2019 and June 2020 using ERIC, SCOPUS, and Web of Science (Web of Science Core Collection and Medline) databases by the first author. Through the Education Research Information Center (ERIC), the most recent results for the terms "feedback" and "motor learning" were determined by means of a keyword search and their content was examined for its thematic fit based on key categories. According to - Table 1, the categories Task, Modality, Setting, and Population were hierarchically decisive for this first assessment. The results were ranked in terms of their relevance and the year of publication. This was followed by screening the title, abstract, and a review of the bibliography for cross-references of the most relevant studies, to identify additional keywords and synonyms according to the categories in - Table 1, which formed the basis of the search strings.

The same procedure was also applied to the other databases, so that manuscripts pertinent to the research question could be identified. In a final step, the identified keywords were used as search terms (- Table 2).

The search identified 11 studies in the different databases for final consideration in the review. - Figure 1 shows the selection procedure. Some studies were excluded for reasons such as topic (e.g., behavior, inclusion), subject (e.g., mathematics, physics), target group (e.g., children with disabilities, preservice teachers only), or the methods used (e.g., tandem teaching, collaborative learning).

All the studies were reviewed using a three-step procedure, starting with the title and abstract and, if the content was suitable, continuing to read the full text. In the final stage, the characteristics listed in - Table 3 had to be included in the studies. An additional researcher inde-
Ger J Exerc Sport Res 2022 $\cdot 52: 447-460$ https://doi.org/10.1007/s12662-021-00782-y (c) The Author(s) 2021

\section{Mödinger $\cdot$ A. Woll $\cdot$ I. Wagner Video-based visual feedback to enhance motor learning in physical education-a systematic review}

\section{Abstract}

While studies have indicated that visual feedback promotes skill acquisition and motor learning in controlled settings and for various sports, less is known about its feasibility in physical education, which has specific needs and conditions. For this reason, a systematic literature review was conducted regarding video-based visual feedback in physical education. Out of 2030 initially examined studies, 11 matched the selection and quality criteria. The goal was to determine whether visual feedback can be effective regarding motor learning in physical education in primary and secondary schools, and to investigate whether different visual feedback variants (expert modeling and self-modeling), supported by verbal feedback, are more effective than verbal feedback alone. Subsequently, the different conditions (e.g., age, group size, duration) of the included studies were evaluated for their suitability for everyday applications. Videobased visual feedback seems to be effective to enhance motor learning in physical education and seems to be more effective than solely verbal feedback. However, the results show that the specific conditions (class size, scheduled lessons, available time, technical equipment, the digital literacy of teachers, and data protection) of a school environment must be considered before implementing visual video feedback in daily practice.

\section{Keywords}

Physical education - Visual feedback . Augmented feedback $\cdot$ Motor learning

pendently repeated the same process to improve the reliability of the results. The consistency in the selection of studies was 99.2\%. Different views were discussed and the final decision was made on the basis of the inclusion criteria using the full text. 


\section{Review}

\begin{tabular}{|c|c|c|}
\hline Database & Results & Search string (exported on 19 June 2020) \\
\hline SCOPUS & 733 & 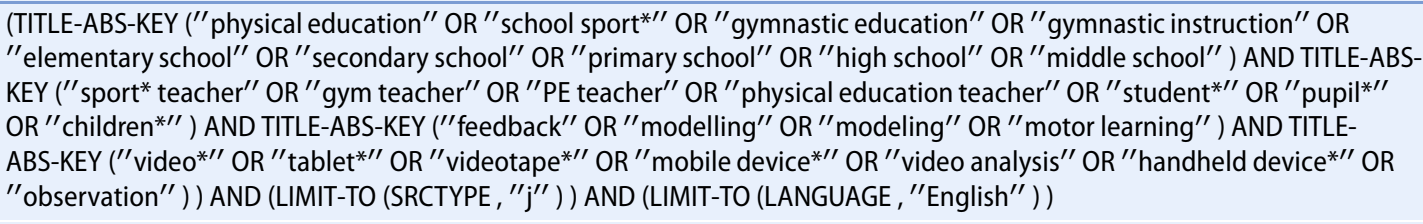 \\
\hline $\begin{array}{l}\text { Web of } \\
\text { Science }\end{array}$ & 405 & 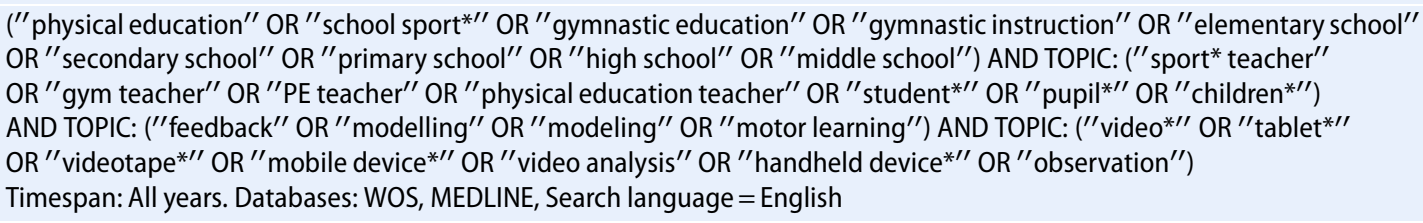 \\
\hline ERIC & 890 & 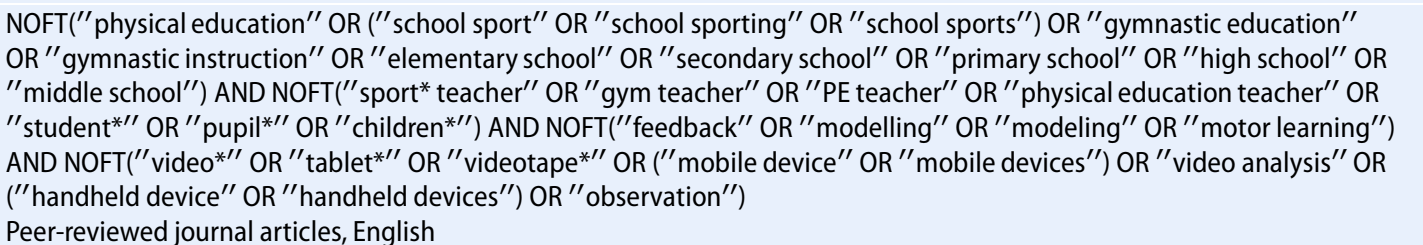 \\
\hline
\end{tabular}

Table 3 Inclusion criteria

Item Description

(A) Did the examination take place in a school context?

Setting The review ruled out studies in associations or in university environments

(B) Was the person giving the feedback skilled and able to correct the students appropriOperator ately?

In the case of a university or comparable educational institute, professional skill was a prerequisite

(C) Were the experimental and control groups made up of students?

Target Due to the fact that, in various countries, the highest level of school education may

population not be reached until after the age of 18 , the age of majority was not an exclusion criterion

(D) Did the learners receive visual feedback by observing their own movement perfor-

Treatment mance?

method Whether the visual feedback showed only learners, or a comparison between their own and expert execution, was irrelevant for the selection

(E) Was the visual feedback delivered via a smartphone, tablet, laptop, or video camera?

Modality

\section{Results}

The following section provides an overview of the studies found using the search strings and their relevant parameters. It contains research results from 1996-2020 from seven different countries and educational systems. The learning groups were different ages (9-15 years old), had different performance backgrounds (beginner and advanced) and were faced with different types (open and closed skills) of learning tasks. There were also differences in feedback type (instant and delayed) and augmented feedback conditions (expert modeling, self-modeling, verbal feedback, and their derivatives). The systematic literature search identi- classes and the different methodological concepts, the studies had weaknesses, especially regarding blinding and concealed allocation.

The presentation of the results in - Table 5 is based on the research questions. For clarity, the numbers of the studies are given instead of the author(s) name(s) in the following. Studies are numbered according their publication dates, starting with the most recent. Since the oldest study worked with different age groups (third and fifth graders) who learned different skills (an overhead pass in basketball and a forehand stroke in tennis), the results will be discussed as $11 \mathrm{a}$ and $11 \mathrm{~b}$, but still treated as a single study.

\section{Effectiveness of visual feedback in physical education} fied 11 studies that met all the inclusion criteria (•Table 3). A quality assessment was conducted on these 11 studies (- Table 4). This involved checking the studies for sample size, control group, and type of data. Only peer-reviewed articles published in English were considered. These criteria were supplemented by an assessment based on the PEDro Scale (Maher, Sherrington, Herbert, Moseley, \& Elkins, 2003). Reliability was verified by another researcher (96\%). Another researcher verified the assessments with a reliability of $96 \%$. Due to the school setting, the organization of teaching in
To answer the first research question ("Is visual feedback effective to enhance motor learning in physical education?"), the results regarding different types of video feedback (visual/verbal feedback and expert modeling/self-modeling) were analyzed. All included studies had at least 1 study group that received visual feedback based on a video of their own movement performance. In ten studies, this visual feedback was supported with additional verbal feedback from the teacher, which was based on the main errors and 

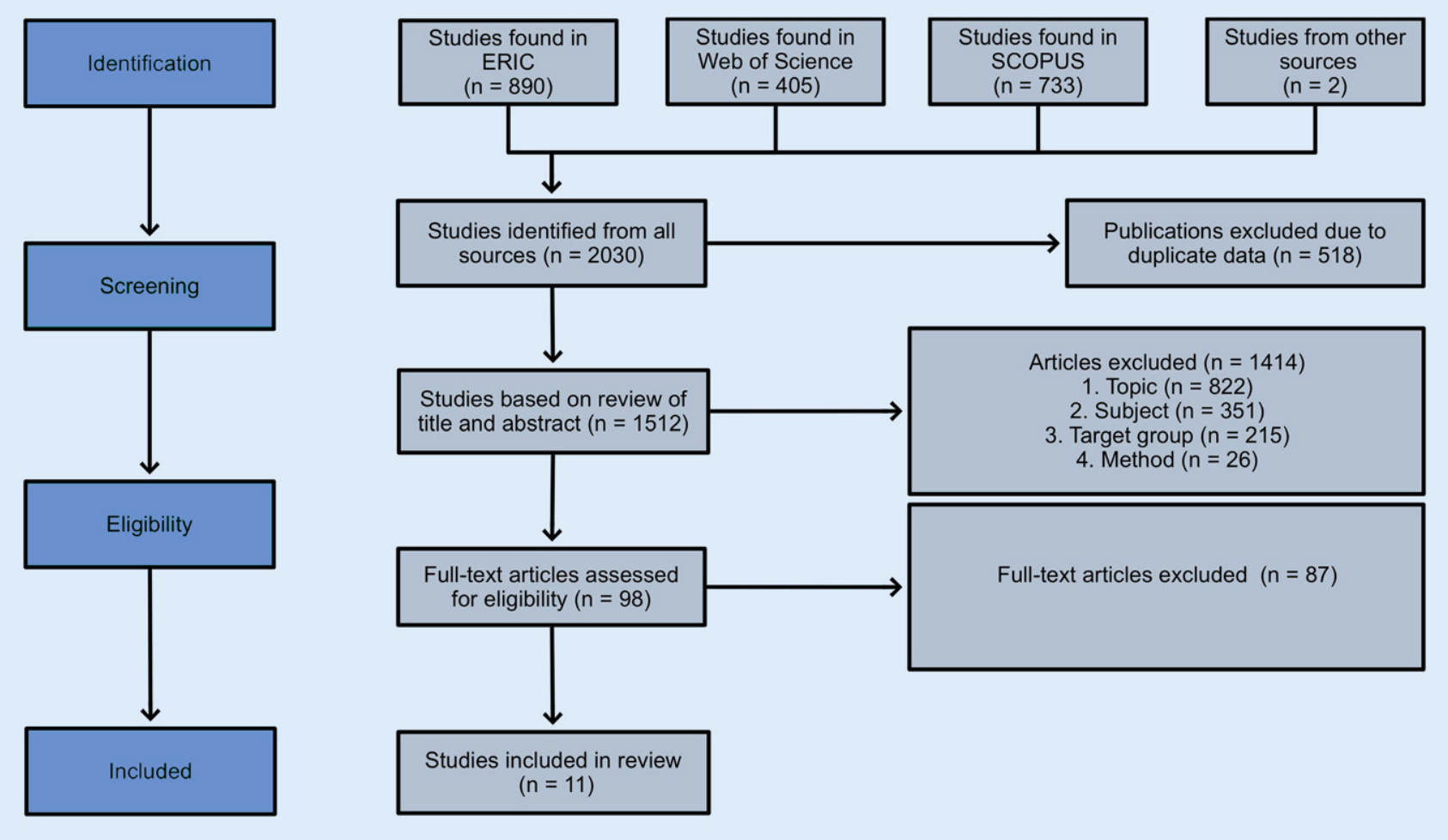

Fig. $1 \Delta$ Identification of included studies based on Moher, Liberati, Tetzlaff, and Altman (2009)

key points $(1,2,3,4,5,6,8,9,10,11 \mathrm{a}$, 11b).

Two studies even videoed the movements in such a way that it was possible for the students to see their movement execution in direct comparison with an ideal movement execution $(4,8)$. One study used a different approach, with the students correcting their own execution by using key points on an observation sheet and, thus, assessing their own execution with regard to strengths and weaknesses (7). For ease of reading in the following, visual feedback consistently includes a verbal feedback component, unless otherwise noted, and thus follows the metaanalysis by Rhoads et al. (2014) on visual feedback in terminology.

The use of video feedback scenarios, which included both expert modeling and self-modeling, led to significant improvements in nine studies $(1,2,3,4,5$, $6,8,9,10)$. In addition, one study supported these findings with focus groups interviews with children and the children's skill self-assessments (7). Another study reported improvements with the use of a qualitative assessment checklist (11a, 11b).
Four studies aimed to compare expert- and self-modeling $(4,8,9,10)$. In two of those studies, participants were able to improve their learning group's skills in volleyball using expert modeling more effectively than by self-modeling $(9,10)$. Another study found comparable improvements in learning to receive and pass the ball in volleyball across all study groups, through verbal feedback, expert modeling with verbal feedback, and expert modeling combined with selfmodeling and verbal feedback (8). Employing a slightly larger sample size and a comparable study design, one study found advantages over verbal feedback for both presented feedbackscenarios (4); however, in this study, expert modeling combined with self-modeling and verbal feedback resulted in better scores than expert modeling with verbal feedback (4).

\section{Visual feedback versus verbal feedback}

To answer to the second research question, a comparison between visual feedback (expert modeling, self-modeling, or a combination of both) and verbal feed- back was conducted. Eight studies using video feedback based on self-modeling made direct comparisons with control groups that received only verbal feedback $(1,2,3,4,5,6,8,11 \mathrm{a}, 11 \mathrm{~b})$.

One study examined third and fifth graders in terms of peer, teacher, and video feedback (self-modeling). They found that the effects for the video feedback group were more positive for the fifth graders who learned the forehand stroke in tennis (11b). The third-grade students achieved the best results with verbal feedback regarding basic technical skills in basketball (11a). With the exception of these third graders (11a) and one verbal control group (8), self-modeling as form of visual feedback was shown to be superior to only verbal feedback in seven of the studies $(1,2,3,4,5,6,11 \mathrm{~b})$.

\section{Conditions in physical education}

To address whether the conditions of the studies were comparable to those in regular school lessons, the results relating to the various conditions to be expected in a school setting (e.g., the type of sports, skill levels, age groups) will be presented 
Table 4 Quality criteria

(20)

Number Author

(1) Nowels and Hewit, 2018

(2) Potdevin et al., 2018

(3) Kretschmann, 2017

Sample size

Total (groups)

22 (2)

$43(2)$

$31(2)$

Barzouka et al., 2015

(5)

(4)

(6)

(7)

(8)

(9)

(10)

(11a)

(11b)

Palao, Hastie, Guerrero Cruz, \& Ortega, 2015

Harvey and Gittins, 2014

$63(3)$

$60(3)$

34 (3)

$22(1)$

O'Loughlin, Chróinín, \& O'Grady, 2013

The PEDro scale was used to assess the quality of each study,

$116(2)$ 2007

Kioumourtzoglou, 2002

51 (3)

51 (3)

$\begin{aligned} & \text { Control } \\ & \text { group }\end{aligned}$
Yes
Yes
Yes

Yes

Pretest

Posttest Retention

Data

test

Yes Yes

Yes Yes

Yes

Yes

No
No

No

No

Yes

Yes

Yes

Yes Yes No

Yes

Yes

Yes

Yes Yes

Yes

No

Quantitative

Quantitative

Quantitative

Qualitative

Quantitative 5

Qualitative

Quantitative 5

Qualitative

Quantitative 5

Qualitative 3

$53(3)$

Yes Yes Yes

Quantitative 6

58 (2)

No

Yes Yes Yes

Quantitative 6

Yes Yes Yes

Yes

Quantitative 6

Yes Yes No

Quantitative

4

Yes

Yes Yes No

Quantitative 5

specific (random assignment, concealed assignment, groups similar at baseline, blinding of subjects, blinding of therapists, blinding of investigators, less than $15 \%$ dropouts, intention-to-treat analysis, statistical comparisons between groups, point measures, and variability data), resulting in a total PEDro score (range $=0-10$ points)

in the following section. The studies included in this review differed with regard to the types of sports that were examined. Team sports-volleyball $(4,8$, $9,10)$, basketball $(7,11 \mathrm{a})$, and football (6) - were analyzed in seven studies, and solo sports-athletics (5), swimming (3), tennis (11b), and gymnastics $(1,2)$ - were investigated in four studies.

The age of participants ranged from 9 (7) to 15 years $(4,5,8)$, while 3 studies provided no age information $(1,3,11 \mathrm{a}$, $11 b)$. The duration $(30-120 \mathrm{~min})$ and length (1-16 sessions) of the interventions also varied between studies, and the selection of skills to be learned emphasized discipline-specific technical skills, with only 1 study focusing on tactical skills (6).

The open-closed continuum developed by Knapp (1963) defined open and closed skills as extremes on a ten-point scale. While closed skills are characterized by a high degree of repeatability under constant conditions, open skills, on the other hand, are to some extent dependent on their environment, for example a player. Based on this classification, open $(4,6$, $8,11 \mathrm{a}, 11 \mathrm{~b})$, closed $(1,2,3,5)$, and com- binations of both types of skills $(7,9,10)$ were represented in the studies.

In terms of the type of feedback, the students received feedback directly after their performance $(1,2,3,5,6,9,10$, $11 \mathrm{a}, 11 \mathrm{~b})$. In two studies, the teachers used videos recorded in the previous lesson due to the time-consuming editing process $(4,8)$.

In total, 18 study groups of different sizes received instruction via video feedback. Only 4 groups $(9,10)$ exceeded the average class size of 23 students in countries of the Organisation for Economic Co-operation and Development (OECD, 2020). The range of sizes in the groups that received verbal feedback varied less, but reached the specified OECD class size only once (2).

\section{Discussion}

The systematic review was conducted to investigate the use of various visually augmented feedback types in physical education to determine the following: first, whether visually augmented and multimodal feedback was effective in physical education; second, whether visually augmented, multimodal feedback variants (expert modeling, self-modeling, or a combination of both) were more effective to enhance motor learning than verbally augmented feedback alone; and third, whether the conditions of the investigations were comparable to those found in regular school lessons.

\section{Effectiveness of visual feedback in physical education}

Verbal feedback is considered to be an important instrument (Rhoads et al., 2014) for improving motor learning. This cannot be easily assumed for visual feedback; however, the fact that the vast majority of studies that used video feedback that included both expert modeling and selfmodeling resulted in significant improvements supports the hypothesis that visual feedback may be suitable to enhance motor learning in physical education.

This was not necessarily to be expected, since both skill levels (Bertram, Marteniuk, \& Guadagnoli, 2007; Rhoads et al., 2014; Rothstein \& Arnold, 1976) and ages (11a, 11b) can have an impact on the benefits of visual feedback. Experi- 


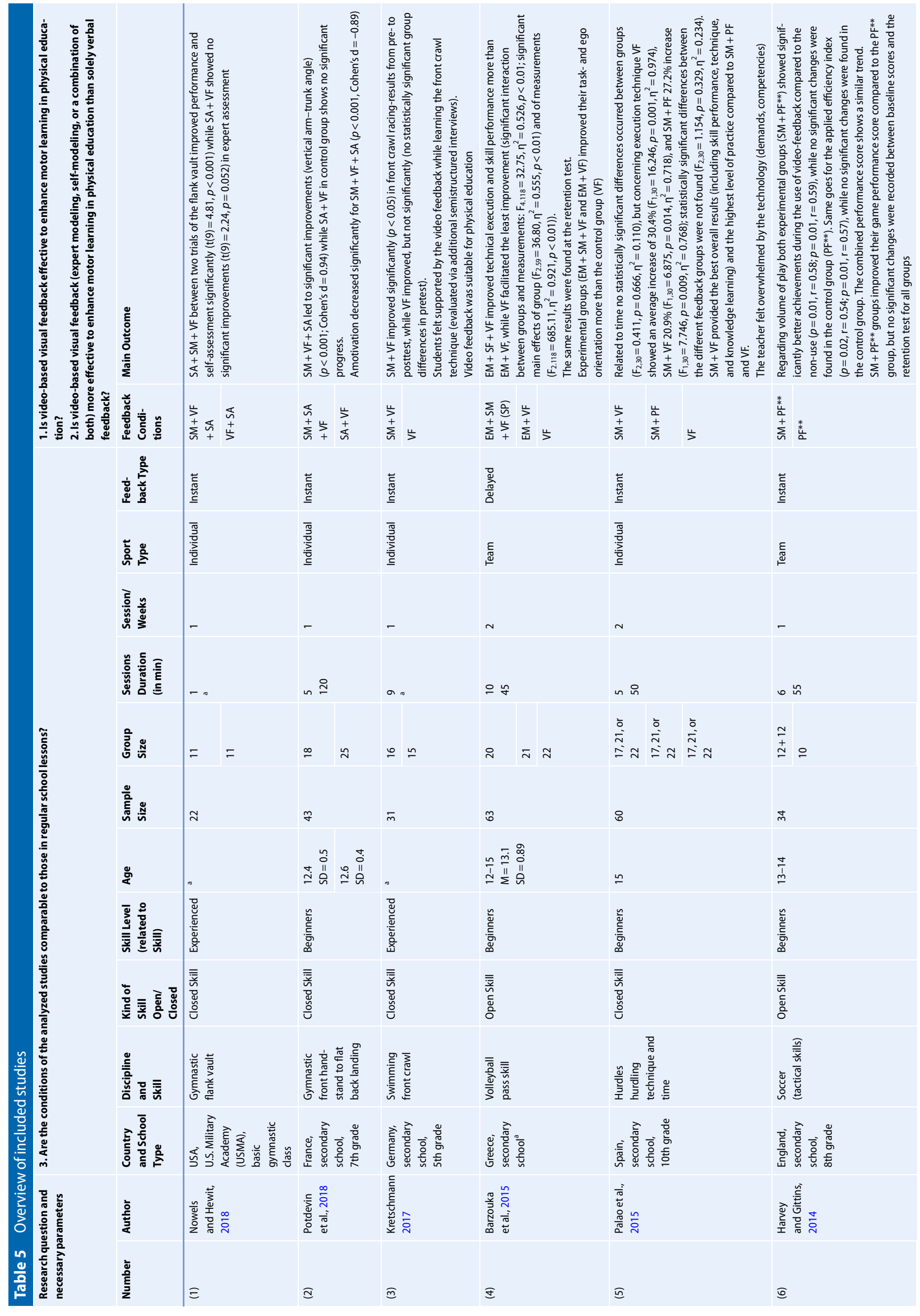




\section{Review}

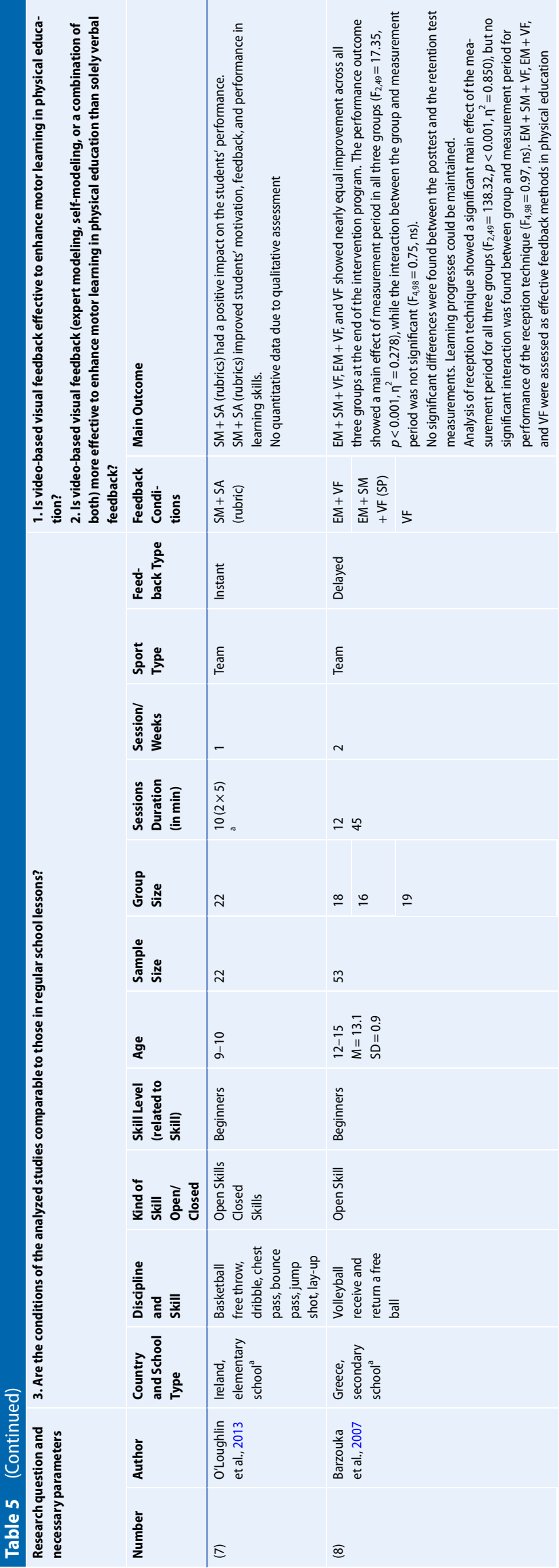




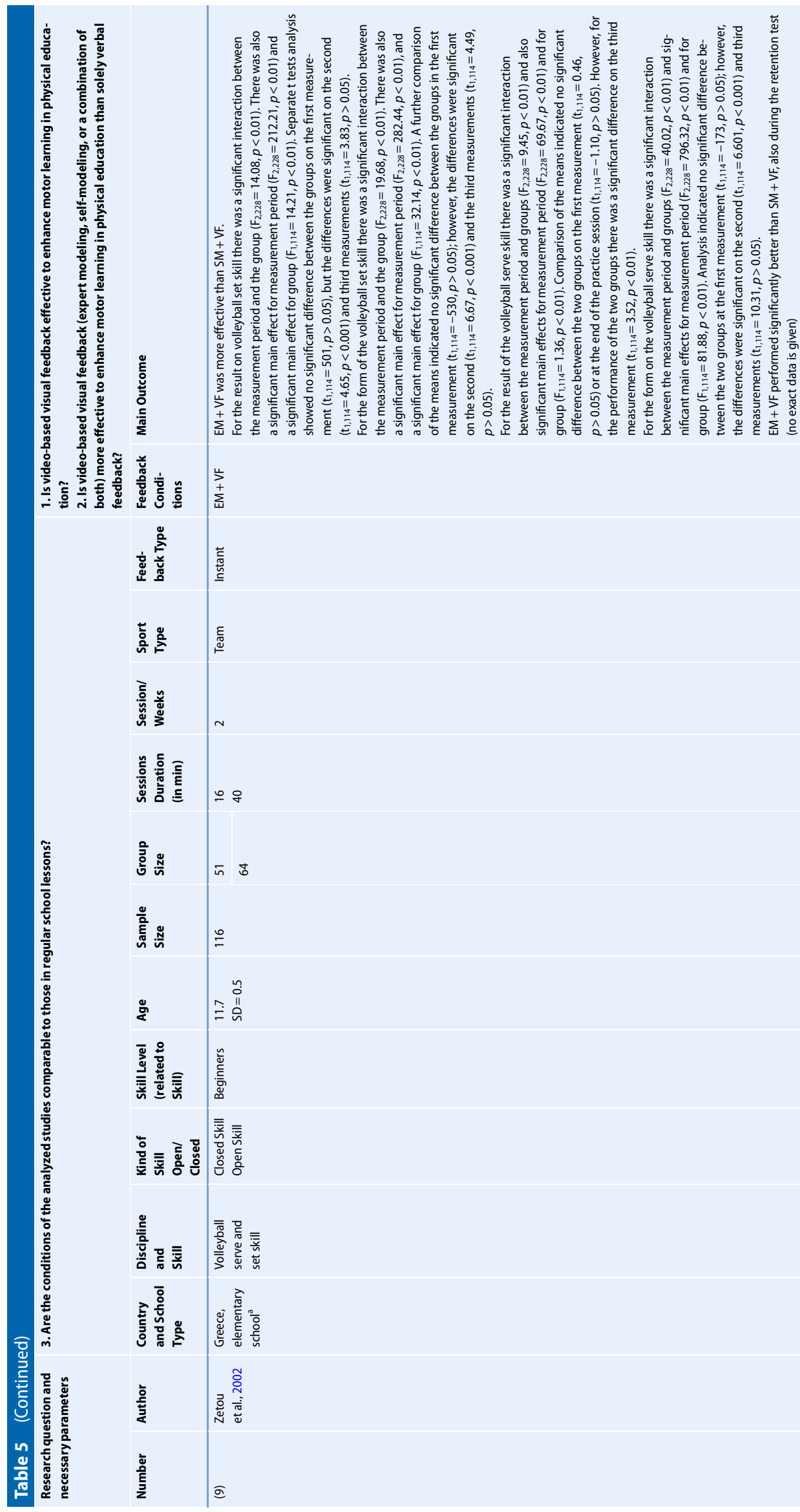




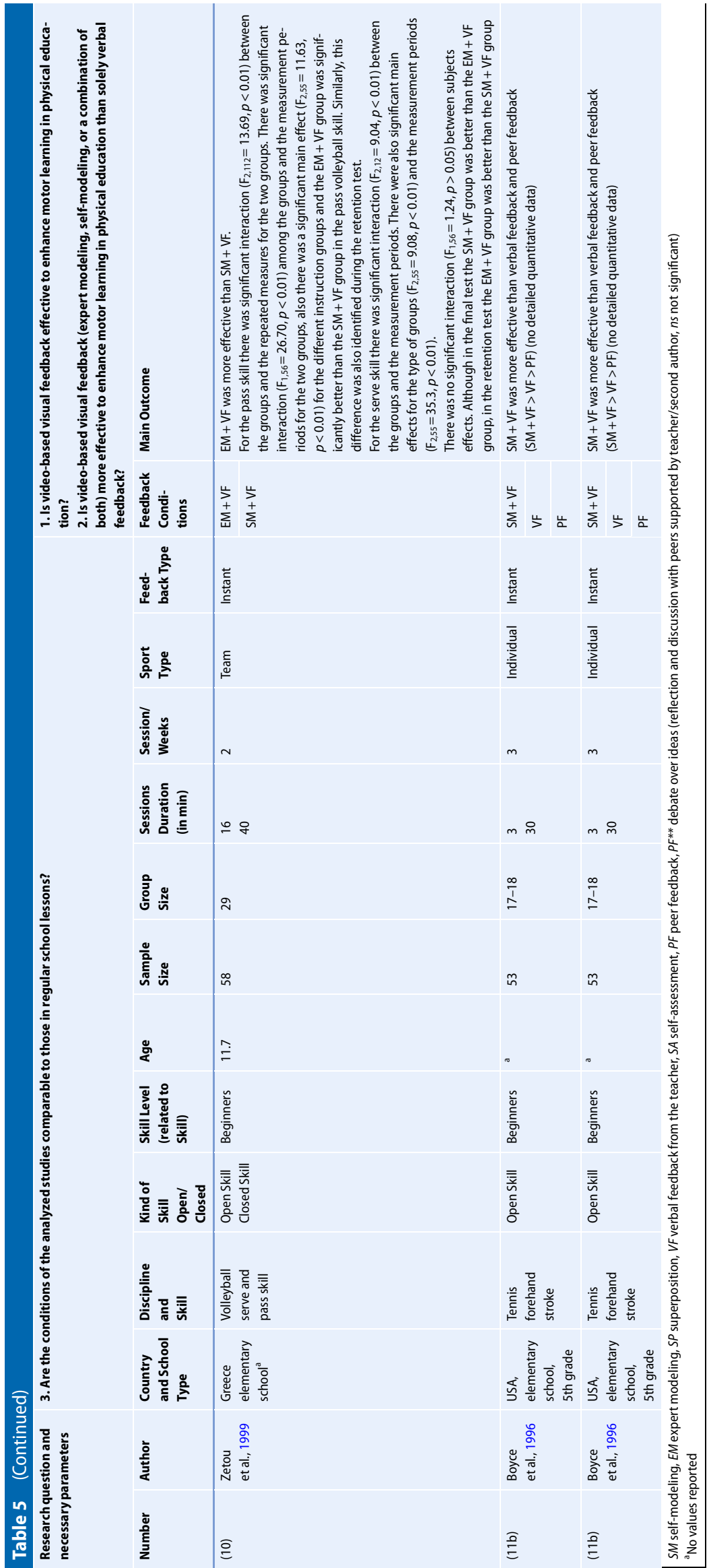

enced and older learners generally obtain greater benefits from it but, since the students in the studies were beginners with regard to the skills to be learned, these differences may have been less relevant.

The comparison of different visual feedback methods not only indicated a general benefit of visual feedback, but also suggested that expert modeling could be more effective in physical education. Four studies in which the expert modeling was compared with another visual feedback method give indications of this. Two studies achieved better results with expert modeling than with selfmodeling $(9,10)$. Assessing one's own movements (self-modeling) generated even greater performance benefits (4) and was possibly enhanced by instant, rather than delayed, feedback (minutes to days; 4, 8) (Rhoads et al., 2014). Nevertheless, this additional benefit could not be conclusively confirmed (8). Students' desire to perform like experts could have been the reason for this improvement, but the process of self-modeling does not incorporate this desire and therefore may not motivate the students in the same way $(9,10)$.

An experienced model is ideal for expert modeling (Lirgg \& Feltz, 1991), but a learning model can also be helpful (McCullagh \& Meyer, 1997). Resulting movement representations can help individuals to identify coordination patterns and thus improve their own movements (Magill \& Schoenfelder-Zohdi, 1996). Another explanation may be that differences in the way verbal feedback is given can also affect motivation, while expert modeling focuses on the execution of the skills, self-modeling focuses on errors. Furthermore, the studies concluded that the integration of expert models in physical education is a timesaving way of providing visual feedback (9); the additional integration of selfmodeling was time-consuming (4), but could possibly be enhanced by mobile devices in the future.

In summary, it must be noted that most of these changes in performance only covered a period of several weeks. Retention tests, regarded as central by Winstein and Schmidt (1990), made 
some study results $(4,6,8,9,10)$ more meaningful.

\section{Visual feedback versus verbal feedback}

Several studies provided indications that visual feedback variants (expert modeling, self-modeling, or a combination of both) were more effective than verbally augmented feedback alone.

Seven studies $(1,2,3,4,5,6,11 \mathrm{~b})$ achieved better results for visual than verbal feedback groups. The reasons for this could be improved visualization, unique information, recognition of errors (Erbaugh, 1985), and the conscious control of attention, which enabled the simultaneous visualization of self-modeling and expert modeling (4). Overall, the review results corresponded to those of Rhoads et al. (2014), whose meta-analysis found small positive effects for visual feedback in motor learning.

Nevertheless, some studies concluded that visual feedback is not superior to verbal feedback $(8,11 a)$. Younger students with less movement experience (11a) benefited less from visual feedback than older students (11b). It may have been more difficult for younger students than older ones to develop cognitive representations, as discussed by Carroll and Bandura (1990), in order to benefit from visual feedback. Verbal feedback seems to be the method of choice for students undergoing the early learning process (Kernodle et al., 2001).

A question remained about the degree of verbal support to be used in combination with visual feedback. Verbal cues play an important role in influencing the situational interests of students receiving visual feedback (Roure et al., 2019), and may be a key factor in making visual information useful.

There is evidence that self-modeling without verbal feedback may be ineffective (Rucci \& Tomporowski, 2010). Although Kok et al. (2020) did not confirm these results, a video model for lessons, and the use of cue cards, provided an opportunity for students to identify their own mistakes, which may have enhanced the verbal feedback. Assuming that error identification is more likely to be possi- ble for advanced or more experienced learners (Schmidt \& Walter, 1984), this could explain the advantages of learning compared to beginners and very young learners.

\section{Conditions in physical education}

When comparing the conditions of the available studies with those of a typical school environment, some of them were likely to correspond (in terms of the type of sports and skills, skill levels, age groups, durations, and length of interventions), while others (in terms of group size, technical equipment, and digital literacy) could only be assessed in a limited way.

\section{Comparable conditions}

Sport types, with the exception of tennis, were oriented toward a wide range of school-related fields. For motivational reasons, it seemed to be irrelevant whether visual feedback was given for individual sports or team sports (Rhoads et al., 2014). Differences in skill levels reflected the range of school diversity, and the ages of the students, if reported, were typical for primary and secondary education. The fact that only 1 session (2) out of 8 studies provided data for sessions lasting longer than $55 \mathrm{~min}$ suggested that this time frame would be adequate in everyday practice for performing video analysis in scheduled lessons $(4,5,6,8,9,10,11 \mathrm{a}, 11 \mathrm{~b})$.

Despite the time-consuming process of video analysis, good results can be achieved in a short time $(30 \mathrm{~min}$ with 16-18 students) (11a, 11b) and in only a few sessions ( $\leq 5$ ) (Rhoads et al., 2014). As a result, the number of feedback loops may be less meaningful than originally assumed. In addition, the use of mobile devices could further accelerate the feedback process in the future (1).

\section{Divergent conditions}

An OECD report (2020) offered an ideal opportunity for comparison, since it covered all the countries examined by the selected studies. The average size of classes at primary level (21 students) and secondary level (23 students) differed slightly; hence, based on this study's results, it was not possible to make any reliable statements regarding the feasibility of considering the group size for the primary level, due to the values being difficult to interpret.

For the secondary education level, none of the video feedback groups reached the average class size specified by the OECD, and some of them were only half that size. This had implications for the validity of the studies for implementing video feedback in daily physical education. The investigated studies did not allow conclusions to be drawn regarding the feasibility of video feedback in physical education for whole secondary school classes.

Furthermore, the inconsistent use of technology played an important role. Recording and playback often occurred separately $(2,4,5,6,7,8,9,10,11 \mathrm{a}, 11 \mathrm{~b})$. Cameras were predominantly used for recording $(2,4,5,6,7,8,9,10,11 \mathrm{a}$, $11 b)$. Equipment used for playback were laptops $(2,5,6)$, monitors $(4,8,9,10)$ or TVs (11a, 11b). Authors often reported using multiple recording and or playback devices $(4,7,8,9,10)$. This has a time impact on preparation, execution, and follow-up. Two studies $(1,3)$ exclusively used a tablet, with applications such as Dartfish, the Hudl technique, or Coach's Eye. They enabled timesaving motion analysis through various functions (freeze, zoom, overlay, slow motion, and delay) and processing options. Kretschmann (2017) confirms the suitability of motion analysis for technology-unfriendly environments such as swimming pools (3). The use of such applications could eliminate the need for extensive technical equipment and complex video editing $(4,8)$ and increase the informative value with respect to the technical conditions. In this context, it is important to consider data protection, which applies to the handling of videos of students' performance.

The use of mobile devices necessitates having teachers with digital literacy who are familiar with the usage of the devices. A lack of technical understanding can influence the use of visual feedback delivered through mobile devices (5), and computer literacy would probably influence the use of technology in 
physical education (3). Many teachers are unfamiliar with the use of technology (Schmid, Goertz, \& Behrens, 2017) and visual feedback (Kretschmann, 2015).

Despite the increasing importance of digitization (especially during a pandemic), many schools even in industrialized countries are under-equipped in terms of digital infrastructure, and many teachers lack digital competence (Schuknecht \& Schleicher, 2020). While technical deficits in the course of digitization could be overcome in the near future, teacher training already requires a well-elaborated concept for teaching digital skills.

\section{Limitations}

This review is the first to systematically examine visual feedback methods in physical education and therefore extends existing knowledge with new findings. However, the review was limited by the small number of available research studies. In addition, in some cases missing data made a systematic evaluation difficult. There was also a lack of information regarding students under 9 years and above 15 years of age. Due to the small number of studies conducted for each age group it was difficult to draw conclusions for certain age groups. Only further findings from investigations in primary and secondary schools could allow definite conclusions to be drawn about the effectiveness of visual feedback in daily physical education. This is likely to be of particular interest, since periods before puberty may be especially beneficial for motor learning (Hirtz \& Starosta, 2002), even if other perspectives exist (Solum, Lorås, \& Pedersen, 2020).

In addition, less than half of the studies performed retention tests, so it was not clear to what extent improvements could be maintained. High-quality studies (e.g., Maher et al., 2003) with appropriate test procedures such as early retention tests, retention tests, and possibly also transfer tests for the development and maintenance of learning progress, as used in other studies (Krause, Buckwitz, \& Olivier, 2010; Stöckel, Hartmann, \& Weigelt, 2007), are required in the future to confirm the suitability of the methods discussed over time.

At this point, it should be pointed out that the data come from different educational systems, so that differences in the conception, design and purposes of physical education may have influenced the results.

\section{Conclusion}

Self-modeling and expert modeling that provide visual feedback in physical education seem to have the potential to improve students' motor performance. The presented evidence suggested that visual feedback methods seem to be more effective than verbal feedback in physical education, possibly due to improved visualization, unique information, and the recognition of errors.

Heterogeneity as well as the motivational elements caused by the institutional settings of schools seem to have less influence on the learning progress, and may be enhanced in physical education compared to sports settings since the tendency to favor visual feedback is also evident in extracurricular sports.

Different influencing factors, such as the size of classes, the time available for giving feedback, the length of scheduled lessons, the available technical equipment, the digital literacy of teachers, and data protection requirements prevent reliable statements being made about the feasibility of visual feedback in daily practice. However, technical developments may help to mitigate the time-consuming nature of the feedback process and increase the practicability of implementing visual feedback in whole classes. The problem of poor digital literacy could be addressed by training qualified teachers and by taking digital literacy into account in the training of new teachers.

Future research is needed to evaluate the different methodological approaches with representative sample sizes, especially in elementary school contexts. In particular, the delivery of combined selfand expert modeling through mobile devices may be promising, especially if expert modeling is used for instruction and, later, for the superpositioning of one's own and the target movement.

\section{Corresponding address

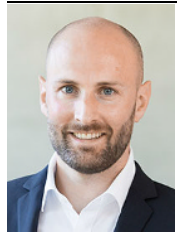 \\ Moritz Mödinger \\ Institut für Sport und \\ Sportwissenschaft (IfSS) \\ \& Forschungszentrum für \\ den Sport von Kindern \\ und Jugendlichen (FoSS), \\ Karlsruher Institut für \\ Technologie (KIT) \\ Engler-Bunte-Ring 15, Geb. \\ 40.40, 76131 Karlsruhe, \\ Germany \\ moritz.moedinger@kit.edu}

Funding. Open Access funding enabled and organized by Projekt DEAL.

\section{Declarations}

Conflict of interest. M. Mödinger, A. Woll and I. Wagner declare that they have no competing interests.

For this article no studies with human participants or animals were performed by any of the authors. All studies performed were in accordance with the ethical standards indicated in each case.

Open Access. This article is licensed under a Creative Commons Attribution 4.0 International License, which permits use, sharing, adaptation, distribution and reproduction in any medium or format, as long as you give appropriate credit to the original author(s) and the source, provide a link to the Creative Commons licence, and indicate if changes were made. The images or other third party material in this article are included in the article's Creative Commons licence, unless indicated otherwise in a credit line to the material. If material is not included in the article's Creative Commons licence and your intended use is not permitted by statutory regulation or exceeds the permitted use, you will need to obtain permission directly from the copyright holder. To view a copy of this licence, visit http://creativecommons.org/licenses/by/4.0/.

\section{References}

Arbabi, A., \& Sarabandi, M. (2016). Effect of performance feedback with three different video modeling methods on acquisition and retention of badminton long service. Sport Science, 9, 41-45.

Bandura, A., \& Walters, R.H. (1977). Social learning theory. Vol. 1. Englewood Cliffs: Prentice Hall.

Barzouka, K., Bergeles, N., \& Hatziharistos, D. (2007). Effect of simultaneous model observation and self-modeling of volleyball skill acquisition. Perceptual and Motor Skills, 104(1), 32-42.

Barzouka, K., Sotiropoulos, K., \& Kioumourtzoglou, E. (2015). The effect of feedback through an expert model observation on performance and learning the passskill in volleyball and motivation. Journa of Physical Education \& Sport, 15(3), 407-416.

Baudry, L., Leroy, D., \& Chollet, D. (2006). The effect of combined self- and expert-modelling on the performance of the double leg circle on the 
pommel horse. Journal of Sports Sciences, 24(10), 1055-1063.

Bellini, S., \& Akullian, J. (2007). A meta-analysis of video modeling and video self-modeling interventions for children and adolescents with autism spectrum disorders. Exceptional Children, 73(3), 264-287.

Bertram, C.P., Marteniuk, R.G., \& Guadagnoli, M. A. (2007). On the use and misuse of video analysis. International Journal of Sports Science \& Coaching,2(1_suppl), 37-46.

Birklbauer, J. (2006). Modelle der Motorik: eine vergleichende Analyse moderner Kontroll-, Steuerungsund Lernkonzepte. Vol. 5. : Meyer \& Meyer.

Blischke, K., Marschall, F., Müller, H., \& Daugs, R. (1999). Augmented information in motor skill acquisition. In Y. V. Auweele, F. Baker, S. Bidle, D. Durand \& R. Seiler (Eds.), Psychology for physical educators (pp. 257-287). Champaign: Human Kinetics.

Boyce, B. A., Markos, N. J., Jenkins, D. W., \& Loftus, J. R. (1996). How should feedback be delivered? Journal of Physical Education, Recreation \& Dance, 67(1), 18-22.

Boyer, E., Miltenberger, R. G., Batsche, C., \& Fogel, V. (2009). Video modeling by experts with video feedback to enhance gymnastics skills. Journal of Applied Behavior Analysis, 42(4), 855-860.

Carroll, W. R., \& Bandura, A. (1990). Representational guidance of action production in observational learning: a causal analysis. Journal of Motor Behavior, 22(1), 85-97.

Clark, S.E., \& Ste-Marie, D. M. (2007). The impact of self-as-a-model interventions on children's self-regulation of learning and swimming performance. Journal of Sports Sciences, 25(5), 577-586.

Dowrick, P.W. (1999). A review of self modeling and related interventions. Applied \& Preventive Psychology, 8(1), 23-39.

Emmen, H. H., Wesseling, L. G., Bootsma, R. J., Whiting, H.T. A., \& van Wieringen, P.C.W. (1985). The effect of video-modelling and video-feedback on the learning of the tennis service by novices. Journal of Sports Sciences, 3(2), 127-138.

Engelkamp, J. (1998). Memory for actions. : Psychology Press, Taylor \& Francis.

Erbaugh, S.J. (1985). Role of visual feedback in observational motor learning of primary-grade children. Perceptual and Motor Skills, 60(3), 755-762.

Guadagnoli, M., Holcomb, W., \& Davis, M. (2002). The efficacy of video feedback for learning the golf swing. Journal of Sports Sciences, 20(8), 615-622.

Harvey, S., \& Gittins, C. (2014). Effects of Integrating Video-Based Feedback into a Teaching Games for Understanding Soccer Unit. Agora Para la Educación Física y el De-porte, Agora for PE and Sport, 16(3), 271-290.

Hirtz, P., \& Starosta, W. (2002). Sensitive and critical periods of motor co-ordination development and its relation to motor learning. Journal of Human Kinetics, 7, 19-28.

Hitchcock, C.H., Dowrick, P.W., \& Prater, M. A. (2003). Video self-modeling intervention in schoolbased settings: a review. Remedial and Special Education, 24(1), 36-45.

Hoffmann, J., \& Engelkamp, J. (2013). Systemmodelle: Sensorische und motorische Prozesse beim episodischen Erinnern. In Lern- und Gedächtnispsychologie (pp. 165-190). Berlin, Heidelberg Springer.

Kelley, H., \& Miltenberger, R.G. (2016). Using video feedback to improve horseback-riding skills. Journal of Applied Behavior Analysis, 49(1), 138-147.

Kernodle, M.W., \& Carlton, L. G. (1992). Information feedback and the learning multiple-degree-offreedom activities. J Mot Behav, 24(2), 187-196.

Kernodle, M.W., Johnson, R., \& Arnold, D. R. (2001). Verbal instruction for correcting errors versus such instructions plus videotape replay on learning the overhand throw. Perceptual and Motor Skills, 92(3 Pt 2), 1039-1051.

Knapp, B. (1963). Skill in sport: the attainment of proficiency. London: Routledge \& K. Paul.

Kok, M., Komen, A., van Capelleveen, L., \& vanderKamp, J. (2020). The effects of self-controlled video feedback on motor learning and self-efficacy in a Physical Education setting: an exploratory study on the shot-put. Physical Education and Sport Pedagogy, 25(1), 49-66.

Korban, S., \& Künzell, S. (2019). Verbesserung der diagnostischen Kompetenz mit iPads ${ }^{\circledR}$ - Ein Ausbildungskonzept. Zeitschrift für Studium und Lehre in der Sportwissenschaft, 2(2), 5-13.

Krause, D., Buckwitz, R., \& Olivier, N. (2010). Videotraining zur Start- und Wendetechnik im Schwimmsport. In Biomechanische Leistungsdiagnostik im Schwimmen (pp. 19-24).

Kretschmann, R. (2015). Effect of physical education teachers' computer literacy on technology use in physical education. Physical Educator, 72(5), 261-277.

Kretschmann, R. (2017). Employing tablet technology for video feedback in physical education swimming class. Journal of e-Learning and Knowledge Society, 13(2), 103-115.

Lirgg, C.D., \& Feltz, D. L. (1991). Teacher versus peer models revisited: effects on motor performance and self-efficacy. Research Quarterly for Exercise and Sport, 62(2), 217-224.

Magill, R. A., \& Schoenfelder-Zohdi, B. (1996). A visual model and knowledge of performance as sources of information for learning a rhythmic gymnastics skill. International Journal of Sport Psychology, 27(1), 7-22

Maher, C.G., Sherrington, C., Herbert, R.D., Moseley, A. M., \& Elkins, M. (2003). Reliability of the PEDro scale for rating quality of randomized controlled trials. Physical therapy, 83(8), 713-721.

Marschall, F., Bund, A., \& Wiemeyer, J. (2007). Does frequent augmented feedback really degrade learning? A meta-analysis. E-Journal Bewegung und Training, 1,74-85.

McCullagh, P., \& Meyer, K. N. (1997). Learning versus correct models: influence of model type on the learning of a free-weight squat lift. Research Quarterly for Exercise and Sport, 68(1), 56-61.

Ministerium für Kultus, J. u. S. M (2016). Bildungsplan des Gymnasiums - Sport. Stuttgart: Ministerium für Kultus, Jugend und Sport.

Moher, D., Liberati, A., Tetzlaff, J., \& Altman, D. G. (2009). Preferred reporting items for systematic reviews and meta-analyses: the PRISMA statement. PLOS Medicine, 6(7), e1000097.

Newell, K. (1991). Augmented information and the acquisition of skill. Sportmotorisches Lernen and Techniktraining, 1,96-116.

Nowels, R. G., \& Hewit, J. K. (2018). Improved learning in physical education through immediate video feedback. Strategies: A Journal for Physical and Sport Educators, 31(6), 5-9.

OECD (2020). Education at a glance 2020: OECD indicators. Paris: OECD Publishing.

Olivier, N., \& Rockmann, U. (2003). Grundlagen der Bewegungswissenschaft und-lehre. Vol. 1. Schorndorf: Hofmann.
O'Loughlin, J., Chróinín, D. N., \& O'Grady, D. (2013). Digital video: the impact on children's learning experiences in primary physical education. European Physical Education Review, 19(2), 165-182.

Palao, J. M., Hastie, P. A., Guerrero Cruz, P., \& Ortega, E. (2015). The impact of video technology on student performance in physical education. Technology, Pedagogy and Education, 24(1), 51-63.

Potdevin, F., Vors, O., Huchez, A., Lamour, M., Davids, K. \& Schnitzler, C. (2018). How can video feedback be used in physical education to support novice learning in gymnastics? Effects on motor learning, self-assessment and motivation. Physical Education and Sport Pedagogy, 23(6), 559-574.

Prater, M.A., Carter, N., Hitchcock, C., \& Dowrick, P. (2012). Video self-modeling to improve academic performance: a literature review. Psychology in the Schools, 49(1), 71-81.

Rhoads, M.C., Da Matta, G. B., Larson, N., \& Pulos, S. (2014). A meta-analysis of visual feedback for motor learning. Athletic Insight, 6(1), 17.

Rothstein, A. L., \& Arnold, R. K. (1976). Bridging the gap: Application of research on videotape feedback and bowling. Motor Skills: Theory into Practice, 1, 35-62.

Roure, C., Méard, J., Lentillon-Kaestner, V., Flamme, X., Devillers, Y., \& Dupont, J.-P. (2019). The effects of vide o feedback on students' situational interest in gymnastics. Technology, Pedagogy and Education, 28(5), 563-574.

Rucci, J. A., \& Tomporowski, P.D. (2010). Three types of kinematic feedback and the execution of the hang power clean. Journal of Strength \& Conditioning Research, 24(3),771-778.

Schmid, U., Goertz, L., \& Behrens, J. (2017). Monitor Digitale Bildung. Die Schulen im digitalen Zeitalter. Report. Gütersloh: Bertelsmann.

Schmidt, R.A. (1975). A schema theory of discrete motor skill learning. Psychological review, 82(4), 225.

Schmidt, R. A. (1991). Frequent augmented feedback can degrade learning: evidence and interpretations. In J. Requin \& G. E. Stelmach (Eds.), Tutorials in motor neuroscience. Behavioral and social sciences, (Vol. 62, pp. 59-75). : Kluwer Academic Plenum Publishers.

Schmidt, R. A., \& Walter, C.B. (1984). Knowledge of results and motor learning: a review and critical reappraisal. Psychological Bulletin, 95(3), 355-386.

Schuknecht, L., \& Schleicher, A. (2020). Digitale Herausforderungen für Schulen und Bildung. ifo Schnelldienst, 73(05), 68-70.

Sigrist, R., Rauter, G., Riener, R., \& Wolf, P. (2013). Augmented visual, auditory, haptic, and multimodal feedbackin motorlearning: a review. Psychonomic Bulletin and Review, 20(1), 21-53.

Solum, M., Lorås, H., \& Pedersen, A. V. (2020). A golden age for motor skill learning? Learning of an unfamiliar motor task in 10-year-olds, young adults, and adults, when starting from similar baselines. Frontiers in psychology, 11, 538-538.

Ste-Marie, D. M., Vertes, K., Rymal, A. M., \& Martini, R. (2011). Feedforward self-modeling enhances skill acquisition in children learning trampoline skills. Frontiers in psychology, 2, 155.

Stöckel, T., Hartmann, C., \& Weigelt, M. (2007). Reihenfolgeeffekte für das Erlernen komplexer sportmotorischer Fertigkeiten auf beiden Körperseiten: Eine Basketballuntersuchung bei Schulkindern. Zeitschrift für Sportpsychologie, 14(3), 130-135. 
Swinnen, S.P. (1996). Information feedback for motor skill learning: a review. In H. Zelanznik (Ed.), Advances in motor learning and control (pp. 37-66). Champaign: Human Kinetics.

Voelcker-Rehage, C. (2008). Motor-skill learning in older adults-a review of studies on agerelated differences. European Review of Aging and Physical Activity, 5(1), 5-16.

Wewetzer, K. (2008). Motorisches Lernen in der Sportart GolfEine empirische Studie mit Anfängern. Doctoral dissertation, Christian-Albrecht University of Kiel..

Winstein, C. J., \& Schmidt, R. A. (1990). Reduced frequency of knowledge of results enhances motor skill learning. Journal of Experimental Psychology-Learning Memory and Cognition, 16(4), 677-691.

Wulf, G., \& Lewthwaite, R. (2016). Optimizing performance through intrinsic motivation and attention for learning: the OPTIMAL theory of motor learning. Psychonomic bulletin \& review, 23(5), 1382-1414.

Wulf, G., Shea, C., \& Lewthwaite, R. (2010). Motor skill learning and performance: a review of influential factors. Medical Education, 44(1), 75-84.

Zetou, E., Fragouli, M., \& Tzetzis, G. (1999). The influence of star and self modeling on Volleyball skill acquisition. Journal of Human Movement Studies, 37(3), 127-143.

Zetou, E., Kourtesis, T., Getsiou, K., Michalapoulou, M. \& Kioumourtzoglou, E. (2009). The effect of selfmodeling on skill learning and self efficacy of novice female beach-volleyball players. Athletic Insight, 10,1-14.

Zetou, E., Tzetzis, G., Vernadakis, N., \& Kioumourtzoglou, E. (2002). Modeling in learning two volleyball skills. Perceptual and Motor Skills, 94(3 Pt2), 1131-1142. 